\title{
Surgical management of idiopathic congenital talipes equinovarus by Carroll twin incision
}

\author{
K. Vijaya Bhaskar Reddy, Narsimha Lavudi*
}

Department of Orthopaedics, MNR Medical College and Hospital, Sangareddy, Telangana, India

Received: 19 August 2020

Revised: 28 September 2020

Accepted: 29 September 2020

\section{*Correspondence:}

Dr. Narsimha Lavudi,

E-mail: luvudi@gmail.com

Copyright: () the author(s), publisher and licensee Medip Academy. This is an open-access article distributed under the terms of the Creative Commons Attribution Non-Commercial License, which permits unrestricted non-commercial use, distribution, and reproduction in any medium, provided the original work is properly cited.

\begin{abstract}
Background: Surgery for congenital idiopathic clubfoot has a number of complications in the postoperative period such as delayed wound healing, gaping, infection, and recurrence of the deformity. The aim of this study is to evaluate the results of primary correction of clubfoot by modified Carroll's double incision technique.

Methods: It is a prospective interventional for a period of 2 years 5 months. 56 foot of which 21 pts have bilateral deformity and 14 pts with unilateral deformity. Patients of 3 months to 2 years age with idiopathic clubfoot, who did not respond to initial Ponseti casting; and were planned for Carroll double incision technique of surgery were included in this study.

Results: In total 56 foot of which male are 23 and female children are 12 in number with male: female ratio of 1.9:1, showing male predominance, 21 pts have bilateral deformity and 14 pts with unilateral deformities. The mean change in radiographic parameters achieved by correction is as postoperative mean talocalcaneal index achieved was $42.6^{0}$ (Normal range $>40^{\circ}$ ). The postoperative mean anteroposterior talo-calcaneal angle was $26.2^{\circ}$ (Normal range $30^{\circ}$ to $55^{\circ}$ ). The Postoperative mean lateral talo-calcaneal angle was $24.4^{0}$ (normal $20^{\circ}$ to $40^{\circ}$ ). Final outcome is $81 \%$ is good, 14 fair and $5 \%$ has poor outcome.

Conclusion: Exposure and release by Carroll's twin incision is good, no tension in sutures, especially medical incision at the time of wound closure.
\end{abstract}

Keywords: Club foot, Carroll's double incision technique, Talo-calcaneal angle

\section{INTRODUCTION}

In the evolutionary process, humans attained bipedal posture mainly attributed to the evolutionary changes of foot. A deformed foot greatly affects the life, man supposed to live.

The incidence of congenital talipes equinovarus (CTEV) is approximately 1-1.4 cases per 1000 live births. Boys are affected twice as often as girls. The etiology of club foot is still obscure although too many theories have been proposed. A higher incidence of CTEV was also noted in patients with a positive family history. ${ }^{1,2}$
Irrespective of the etiology, the pathoanatomic changes associated with CTEV include ankle equinus, a calcaneum that is in equinus and inverted position beneath the talus and the talar head prominence at the dorsolateral midfoot, navicular medial and plantar to the talar head, cuboid medial and in front of calcaneum, medial tilting of anterior part of talus, shortened talar neck, narrow posterior ankle mortise, talar tilt out of ankle mortise.

Multiple types of surgical approaches have been described in literature with the aim to reduce the complications and give adequate tissue exposure so as to release all contractures and allow the incision to heal primarily 
without wound dehiscence or scar contracture. Used twin incisions, a modification of NC Carroll's technique making it simpler for the correction of the idiopathic clubfoot to avoid the above-mentioned complications. In this technique two incisions are given, sparing the mid incision zone of Turco's incision, reducing the chances of gaping or infection. Dual incisions have been also described by Carroll. ${ }^{3,4}$ The aim of this study is to evaluate the results of primary correction of clubfoot by modified Carroll's double incision technique.

\section{METHODS}

It is a prospective interventional study carried out at a tertiary care medical college and hospital in department of Orthopaedics from August 2017 December 2019 i.e. 2 year 5 months. 56 foot of which 21 pts have bilateral deformity and 14 pts with unilateral deformity. Patients of 3 months to 2-year age (most of the kids at 6 months age) with idiopathic clubfoot presenting to the outpatient department, who did not respond to initial Ponseti's casting; and were planned for Carroll double incision technique of surgery were included in this study. Ethical clearance of institution and also informed consent was obtained.

Inclusion criteria included children between 3 months to 2 years age (most of the kids at 6 months age), prior cast application done for all average 5-8 cast, other congenital anomalies ruled out, cardiac evaluation done in all patients before surgery and post operation follow up minimum 6 months for all cases.

Exclusion criteria excluded children below 3 months and after 2 years are not included in study, who are treated with Ponseti method with satisfactory correction, residual or resistant club foot in older children, club foot secondary to cerebral palsy, arthrogryposis multiplex congenita, myelodysplasia (or) congenital dislocation of hip. Patients unfit for surgery.

All the club feet were initially treated by serial long leg plaster of Paris cast using kite's method up to the age of 4 months or 6 to 7 cast. ${ }^{10}$ Plasters were changed every 2 weeks. After it was determined that the deformity could not be corrected with 4 months of serial casting, the feet was considered resistant and surgery was contemplated.

Routine examination of blood including TC, DC, ESR, $\mathrm{Hb} \%$, CT, BT, Routine urine examination, HIV-I, II and HBsAg were done in all patients. All the cases had preoperative radiographs to assess degree of deformity. Radiographic assessment consisted of anteroposterior talocalcaneal angle, lateral talocalcaneal angle and talocalcaneal index.

Surgical technique performed under general anaesthesia in a semi lateral position, operated all the cases. Tourniquets were not used during the surgery.

\section{Double incision}

\section{Curvilinear medial incision}

The landmarks for the medial incision are the centre of the OS calcis, the front of the medial malleolus and the base of the first metatarsal. These three points define a triangle. The incision is parallel with the base of the triangle but curved in the plantar direction proximally and over the dorsum of the foot distally.

\section{Posterolateral incision}

It runs obliquely from the midline of the distal calf posteriorly to a point midway between the tendo calcaneus and the lateral malleolus.

\section{Procedure}

Through the posterolateral incision, the sural nerve and short saphenous vein were identified and protected. Lengthening of tendo calcaneus was done by a sagittal ' $Z$ ' plasty technique detaching the medial half of the tendon from the calcaneus. The deep fascia overlying the flexor hallucis longus and neurovascular bundle is opened. Tibialis posterior was identified and lengthened. The posterior and lateral capsule of ankle and subtalar joint was opened. The tight posterior calcaneofibular and posterior talofibular ligaments were divided. The posterior portion of the deltoid ligament was divided.

Through the medial incision, the abductor hallucis was freed from the OS calcis. The plantar fascia was incised and Henry's knot was sectioned. The flexor hallucis longus and flexor digitorum longus together with the neurovascular bundles were retracted in the plantar direction. The long and short plantar ligaments were divided. Calcaneonavicular ligament was divided. Capsulotomy of the talonavicular joint and calcaneocuboid joint were done. With the foot in a plantigrade position, verified correction obtained. In needed cases, intramuscular recession of flexor hallucis longus and flexor digitorum longus tendon were done. With the foot held in plantigrade position, the tendo calcaneus and tibialis posterior were repaired. Wound closed and compressive dressing applied. Above knee slab applied. Not used ' $\mathrm{K}$ ' wire to stabilize the joint.

\section{Postoperative protocol}

Under anaesthesia on $14^{\text {th }}$ postoperative day, removed the sutures and applied long leg cast with knee in $70^{\circ}$ flexion and ankle and foot in neutral position.

On subsequent follow up, applied plaster of Paris cast for 8 weeks postoperative period. The cast was changed every 2 weeks. Applied orthosis subsequently till the child started walking. Later clubfoot boot was given to maintain correction. Postoperative radiographs were taken to assess radiological correction. 
From the original Carroll double incision technique, adopted the following modifications. Operated all the cases in semi lateral position. Not used ' $\mathrm{K}$ ' wire to stabilize the joint. Applied plaster of Paris slab with knee in flexion in the immediate postoperative period.

Evaluated the results using Dimeglio method of grading severity of clubfoot. Each major component of clubfoot (ankle equinus, heel varus, derotation of calcaneopedal block and forefoot adductus) are graded clinically from 4 to 1 (most severe to mild). ${ }^{5}$

During the follow up period, each foot was evaluated cosmetically and functionally and rated accordingly. Good- clinically well aligned foot, no residual or very minimal adduction deformity and ankle dorsiflexion of more than $10^{\circ}$ above the normal and ability to evert the foot to neutral position. Fair- correction acceptable in appearance with minimal residual deformity, ability to dorsiflex the ankle to neutral position. Poor- activity limited residual deformity such as hindfoot, adduction, heel varus, inability to dorsiflex and evert the foot to neutral position etc.

The maximum follows up was 14 months. Average follow up was 10 months.

Statical analysis done by using MS excel and it was statistically analysed using Statistical package for social sciences (SPSS version 20) for MS windows. Descriptive statistical analysis was carried out to explore the distribution of several categorical and quantitative variables. Categorical variables were summarized with $\mathrm{n}$ (\%), while quantitative variables were summarized by mean \pm SD. All results were also presented in tabular form and are also shown graphically using bar diagram or pie diagram as appropriate.

\section{RESULTS}

In total 56 foot of which 21 pts have bilateral deformity and 14 pts with unilateral deformities, males are 23 and female children are 12 in number with male:female ratio of 1.9:1, showed male predominance. Bilateral involvement is mostly involved and grade 4 is the preoperative grading severity.

The mean change in radiographic parameters achieved by correction is as post-operative mean talocalcaneal index achieved was $42.6^{\circ}$ (normal range $>40^{\circ}$ ). The postoperative mean anteroposterior talocalcaneal angle was $26.2^{0}$ (normal range $30^{\circ}$ to $55^{\circ}$ ). The Post-operative mean lateral talocalcaneal angle was $24.4^{0}$ (normal $20^{\circ}$ to $\left.40^{0}\right)$.
Table 1: Demographic details of patients.

\begin{tabular}{|lll|}
\hline $\begin{array}{l}\text { Age } \\
\text { (months) }\end{array}$ & $\begin{array}{l}\text { Number of } \\
\text { patients }\end{array}$ & $\begin{array}{l}\text { Percentages } \\
(\%)\end{array}$ \\
\hline $\mathbf{3 - 5}$ & 9 & 25.7 \\
\hline $\mathbf{5 - 8}$ & 14 & 40 \\
\hline $\mathbf{9 - 1 2}$ & 6 & 17.14 \\
\hline $\mathbf{1 3 - 1 6}$ & 3 & 8.5 \\
\hline $\mathbf{1 7 - 2 0}$ & 2 & 5.7 \\
\hline $\mathbf{2 1 - 2 4}$ & 1 & 2.8 \\
\hline Total & 35 & 100 \\
\hline Gender & & \\
\hline Males & 23 & 65.71428571 \\
\hline Females & 12 & 34.28571429 \\
\hline Involved side & & \\
\hline Unilateral & 14 & 25 \\
\hline Bilateral & 21 (42 foot) & 75 \\
\hline Preoperative grading of severity & \\
\hline Grade-3 & 21 foot & 37.5 \\
\hline Grade-4 & 35 foot & 62.5 \\
\hline
\end{tabular}

Table 2: Radiological evaluation in present study.

\begin{tabular}{|llll|}
\hline Angle/index & $\begin{array}{l}\text { Pre- } \\
\text { operative } \\
\text { value }\end{array}$ & $\begin{array}{l}\text { Post- } \\
\text { operative } \\
\text { value }\end{array}$ & $\begin{array}{l}\text { Mean } \\
\text { change }\end{array}$ \\
\hline $\begin{array}{l}\text { Antero posterior } \\
\text { talocalcaneal } \\
\text { angle }\end{array}$ & $13.4 \pm 4.35$ & $26.2 \pm 5.61$ & 12.8 \\
\hline $\begin{array}{l}\text { Lateral } \\
\text { talocalcaneal } \\
\text { angle }\end{array}$ & $16 \pm 3.21$ & $24.4 \pm 7.3$ & 8.4 \\
\hline $\begin{array}{l}\text { Talocalcaneal } \\
\text { index }\end{array}$ & $18.5 \pm 5.76$ & $42.6 \pm 4.32$ & 24.4 \\
\hline
\end{tabular}

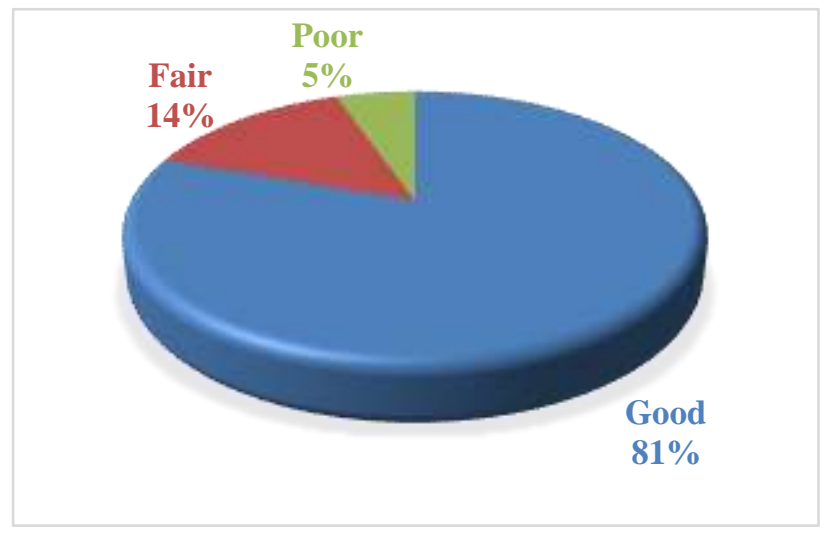

Figure 1: Final outcome of present study.

Final outcome is $81 \%$ is good, 14 fair and $5 \%$ has poor outcome. 


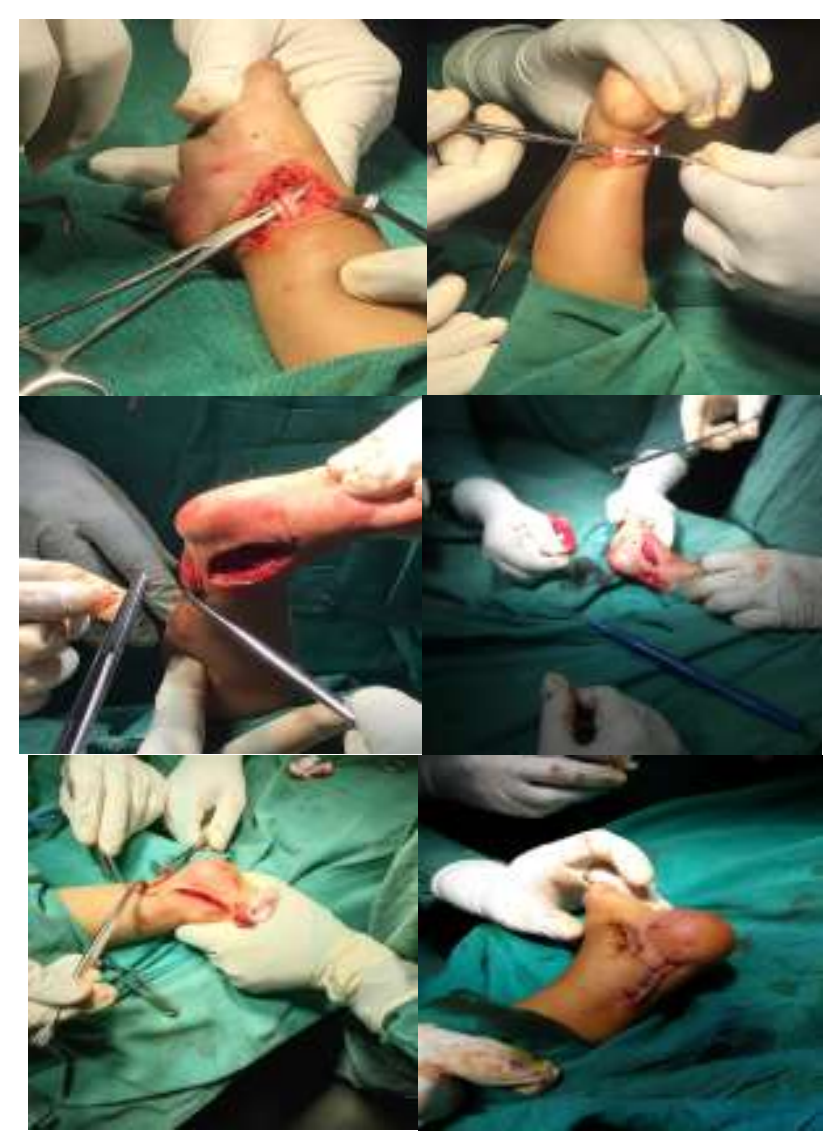

Figure 2: Intraoperative CTEV correction by Carroll's twin incision.

\section{DISCUSSION}

The club foot deformity seems to be induced by an unknown dysfunction in the territory subtended by posterior tibial nerve below knee with excess collagen synthesis a retracting fibrosis in posteromedial structures. prenatal early club foot evaluation can be done at $14^{\text {th }}$ week of pregnancy by trans vaginal ultrasonography. serial evaluation is required to detect late onset club foot. After birth Ponseti serial cast technique greatly reduced the need of surgery, scar, stiffness and weakness. As club foot is primarily a soft tissue deformity followed by bony changes, various soft tissue procedure is present for club foot correction.

In this study male:female ratio is 1.9:1 (23 males and 12 females), nearly all studies have demonstrated a higher prevalence of clubfoot in males than in females. Male:female ratios of idiopathic clubfoot range from $2.5: 1$ to $1.6: 1$, although it is nearly $4: 1$ in Australian Aborigines. ${ }^{1,6.7}$ A male bias was also consistent across a series of eighty-four patients with non-idiopathic clubfoot, despite these individuals having diverse neuromuscular and genetic causes of the clubfoot. ${ }^{8}$

Compared the results with those of other published studies and found a bilateral versus unilateral ratio of $3: 1$ comparable to that of Turco $155: 45 .{ }^{9}$ Skin necrosis rate as described by Turco in was 6\%, and Aggarwal et al was $3 \% .{ }^{10}$ However, found no skin necrosis following the technique of two incisions. However, surgically treated clubfeet, in which at least part of the retracted ligaments are removed and the tendons are lengthened, frequently relapse as well, presumably due to surgical scar and muscle fibrosis. ${ }^{11}$ The overall results as reported by Turco for his procedure on 31 cases in 1971 was $90 \%$ success and $10 \%$ failure. ${ }^{9}$ In this series, outcome is $81 \%$ is good, 14 fair and $5 \%$ has poor outcome. The clinical and radiological results of this study are comparable to studies by Varma et al, Yamamoto et al and Kaewpornsawan K et al who showed excellent results with PMSTR and also appreciable improvement in radiological parameters. ${ }^{12,13,14}$

Carroll et al reviewed their results and found that $81 \%$ of the patients had a satisfactory result. Dimeglio et al believed that the extent of the surgery should be matched to the complexity of the club foot deformity 'a la carte' approach. ${ }^{5}$ Yoneda et al reviewed the results of surgical correction of 84 severe clubfeet by Carroll's double incision technique at 5 years follow up. ${ }^{15}$ They achieved good results in $82 \%$ cases. Porat et al 14 reviewed 33 severe clubfeet treated by Carroll's double incision technique after an average of 5 years follow up. ${ }^{19} 82 \%$ cases had satisfactory results. Haasbeck et al reviewed 58 severe clubfeet treated surgically using Carroll's approach after an average follow up of 5.5 years. ${ }^{16} 85 \%$ cases had good results. Roye et al in their study compared long term results of the Carroll procedure with those of limited posterior release. ${ }^{17}$ They found that patients undergoing the Carroll procedure had significantly fewer surgeries and less stiffness. Haesbeck et al found that on an average of 28 years after surgery, patients who had comprehensive release had fewer operations, more complete correction of heel varus and improved subtalar motion when compared to those with isolated posteromedial release. ${ }^{16}$

Table 3: Study.

\begin{tabular}{|c|c|c|}
\hline Study & No. of club feet & Results (\%) \\
\hline${\text { Yoneda et } \text { al }^{15}}^{15}$ & 84 & 82 good \\
\hline Hwan-Tak ${ }^{18}$ & 58 & 85 good \\
\hline Porat et al ${ }^{19}$ & 33 & 82 good \\
\hline Turco 9 & 31 & 90 \\
\hline Varma et al ${ }^{12}$ & 73 & 81 \\
\hline Present & 56 & 81 \\
\hline
\end{tabular}

Carroll's approach provides good exposure of the entire pathological anatomy without compromising wound healing. Especially in severe cases, the posterolateral tether is the main causative factor for equinus deformity. Carroll's approach allows good access to the entire posterior aspect of ankle and subtalar joint.

\section{CONCLUSION}

Carroll's dual incision technique offers goods exposure to the posterolateral, subtalar and medial structures without wound healing problems. This technique gives supple and 
cosmetic foot. With the limited experience in this technique, it is definitely a procedure of choice in the surgical management of severe resistant club foot.

Funding: No funding sources

Conflict of interest: None declared

Ethical approval: The study was approved by the institutional ethics committee

\section{REFERENCES}

1. Lochmiller C, Johnston D, Scott A, Risman M, Hecht JT. Genetic epidemiology study of idiopathic talipes equinovarus. Am J Med Genet. 1998;79(2):90-6.

2. Byron-Scott R, Sharpe P, Hasler C, Cundy P, Hirte C, Chan A et al. A South Australian population-based study of congenital talipes equinovarus. Paediatr Perinat Epidemiol. 2005;19:227-37.

3. Carroll NC. Congenital clubfoot: Pathanatomy and treatment. Instr Course Lect. 1987;36:117-21.

4. Carroll NC, McMurtry R, Leete SF. The pathoanatomy of congenital clubfoot. Orthop Clin North Am. 1978;9:225-32.

5. Dimeglio A, Bensahel H, Souschet P, Mazeau P, Bonnet F. Classification of clubfoot. J Pediatr Orthop B. 1995;4(2):129-36.

6. Rebbeck TR, Dietz FR, Murray JC, Buetow KH. A single-gene explanation for the probability of having idiopathic talipes equinovarus. Am J Hum Genet. 1993;53:1051-63.

7. Lochmiller C, Johnston D, Scott A, Risman M, Hecht JT. Genetic epidemiology study of idiopathic talipes equinovarus. Am J Med Genet. 1998;79:90-6.

8. Chakraborty R. The inheritance of pyloric stenosis explained by a multifactorial threshold model with sex dimorphism for liability. Genet Epidemiol. 1986;3:115.

9. Turco VJ. Surgical correction of resistant clubfoot. One-stage posteromedial release with internal fixation: A preliminary report. J Bone Joint Surg. 1971;53:477-97.

10. Aggarwal ND, Singh HS, Mittal RL. Evaluation of tibialis posterior transfer on surgical treatment of congenital clubfoot. IJS. 1967;29:4-105.

11. Goldner JL, Fitch RD. Classification and evaluation of congenital talipes equinovarus. The clubfoot. 1994;120-39.

12. Varma HS, Agrawal AC, Singh PK. Surgical management of congenital idiopathic clubfoot by twin incisions. J Orthop Allied Sci. 2013;1:18-21.

13. Yamamoto H, Muneta $\mathrm{T}$, Ishibashi $\mathrm{T}$, Furuya $\mathrm{K}$. Posteromedial release of congenital club foot in children over five years of age. J Bone Joint Surg Br. 1994;76(4):555-8.

14. Kaewpornsawan K, Khuntisuk S, Jatunarapit R. Comparison of modified posteromedial release and complete subtalar release in resistant congenital clubfoot: a randomized controlled trial. J Med Assoc Thai. 2007;90(5):936-41.

15. Yoneda B, Carroll NC. One stage surgical management of Resistant Clubfoot: J Bone Joint Surg. 1984;66:30

16. Haasbeck JF, Wright JG. A comparison of the longterm results of posterior and comprehensive release in the treatment of clubfoot. J Pediatr Orthop.1997;17:29.

17. Roye DP, Roye BD. Long term results of Carroll's approach: J Am Acad Orthop Surg, 2002;10:239-248.

18. Hwan-Tak H, Eng-Hin L. Surgical results of clubfoot using Carroll's approach: J Orthopaedic Surg. 1997.

19. Porat S, Kaplan L. Critical Analysis of results in clubfeet treated surgically along the Norris Carroll approach; J Pediatr Orthop. 1989;9:137-43.

Cite this article as: Reddy KVB, Lavudi N. Surgical management of idiopathic congenital talipes equinovarus by Carroll twin incision. Int $\mathbf{J}$ Res Orthop 2020;6:1269-73. 